\title{
Maternal and neonatal outcome of twin pregnancies with single fetal demise
}

\author{
Gunjan Rai ${ }^{1 *}$, Sudhir Mansingh ${ }^{1}$, Bikram Bhardwaj $^{2}$
}

\author{
${ }^{1}$ Department of Obstetrics and Gynecology, Command hospital, Lucknow, Uttar Pradesh, India \\ ${ }^{2}$ Department of Obstetrics and Gynecology, Armed Forces Medical College, Pune, Maharashtra, India
}

Received: 20 June 2021

Revised: 21 July 2021

Accepted: 22 July 2021

\author{
*Correspondence: \\ Dr. Gunjan Rai, \\ E-mail: gunjanraims24@gmail.com
}

Copyright: ( ) the author(s), publisher and licensee Medip Academy. This is an open-access article distributed under the terms of the Creative Commons Attribution Non-Commercial License, which permits unrestricted non-commercial use, distribution, and reproduction in any medium, provided the original work is properly cited.

\begin{abstract}
Background: In current study we managed twin pregnancies having single fetal demise with a successful outcome. Generally monochorionic and monoamniotic pregnancies are having high probability of complications, so we have to be more watchful in these pregnancies. Termination of pregnancy is not the only option as we can manage and prolong pregnancies with a good outcome by strict monitoring of patients. Aim of our study was to look for fetomaternal outcome in twin pregnancies with single fetal demise.

Methods: This is a retrospective study done between July 2017 to June 2020 at Command hospital, Panchkula, Haryana. Total 3249 deliveries have been conducted during above said period. Out of which 47 deliveries were having twin pregnancy. We had six twin pregnancies who reported with one fetal demise. These cases were managed with regular monitoring of coagulation profile and strict fetal surveillance for surviving twin. The cases were studied for antenatal, postnatal and any neonatal complication.

Results: No antenatal, postnatal maternal or any neonatal complication observed in this study. During study period we delivered total 3249 patients, out of which 47 were twin pregnancy. Out of these 47 (1.44\%) twins' pregnancies 33 (70.31\%) were DADC and 14 (29.69\%) DAMC. We studied six twin pregnancies who had single fetal demise.

Conclusions: Even with single fetal demise pregnancies can be continued till term with strict monitoring for maternal and fetal complications. Termination is not the only answer in twin pregnancies with single fetal demise. Although our study was small, it indicates that in case of twin pregnancy with single fetal death and under good surveillance, the live fetus can be salvaged.
\end{abstract}

Keywords: Monochorionic, dichorionic, TTTS, Rh isoimmunization

\section{INTRODUCTION}

Twin pregnancies has increased in past few years due to advance age of marriage and using ART techniques for pregnancy. Generally twin pregnancy are at high risk for complications in form of aneuploidy, single fetal demise, placental and structural abnormality, when we compare with singleton pregnancy. Twin pregnancies are having some similar complication as singleton pregnancy like placenta previa, placental abruptions, vasa previa etc. Monochorionic and monoamniotic pregnancies are having some specific complication like TTTS and cord entanglement. In these pregnancies a early diagnosis is required to plan management, so these pregnancies should be followed with two weekly ultrasound after a certain POG to detect early complications. Chorionicity and amnionicity should be determined in early gestation so we can be more watchful in monochorionic and monoamniotic pregnancies. Post delivery pathological examination of placenta in twin pregnancies gives a clue about cord and placental abnormality and also gives information about chorionicity which helps in 
identification of mechanism of disease affecting twin pregnancies.

ART started in late 1970 's and since then multifetal gestation increased all over the world. The latest centres for disease control and prevention report on ART surveillance indicates that $43 \%$ twin gestation was there in USA in 2011 after treatment with ART. ${ }^{1}$ Twin pregnancy is always associated with higher incidence of risk for both mother and fetus in compare to singleton pregnancy. The main risks are early and late miscarriage, antepartum haemorrhage, postpartum haemorrhage, preterm delivery, single fetal growth restriction, high chances of aneuploidy, TTTs , structural defects and still births. ${ }^{2}$

Twins are also more prone to develop birth asphyxia, hyaline membrane disease, seizure and long term neurodevelopmental morbidity. If we compare overall perinatal mortality in twin it is fourfold higher than singleton pregnancy. ${ }^{3}$ Various studies have proven that in vitro fertilization is associated with higher incidence of structural defect in fetus. ${ }^{4}$ However the lack of information on the etiology of the infertility, chorionicity, pre-existing maternal medical condition and environmental factors in remote areas where facilities are not available and pregnancy get complicated leading to demise of either one or both foetuses. A recent large Australian cohort study showed that the increased risk of birth defects associated with IVF is no longer significant after adjustment of parental factors. ${ }^{5}$ Always monochorionic and monoamniotic twins are at higher risk for intrauterine demise. A dichorionic and diamniotic placenta can be found in both monozygotic and dizygotic twins whereas monochorionic placenta is mainly associated with monozygotic twins. ${ }^{5}$

Overall perinatal mortality is around $11 \%$ in monochorionic twins and in DC twins it is only $5 \%$. Monochorionic monoamniotic twins are rare $(1 \%$ of $\mathrm{MZ}$ twins) but is responsible for highest morbidity and mortality amongst all kind of twin pregnancy. ${ }^{6}$ Hence early establishment of chorionicity and amnionicity is essential to monitor and optimize treatment for twin pregnancy with good outcome. The detection of chorionicity and amnionicity in twin with $98 \%$ accuracy is at 7-9 weeks of gestation. ${ }^{7}$ Accuracy is higher for DC twins than MC twins and is related to the gestational a great which the ultrasound done. Sometimes there are fused placentas where it can be differentiated from monochorionic by Lambda sign.

Ultrasound of twin pregnancy at 10-14 weeks gestation identify chorionicity with a higher degree of accuracy using lambda sign, twin peak sign and thickness of intertwin membrane (thicker in DADC than MAMC pregnancies). Two different placenta and different fetal gender identify a DC pregnancy. When there is only one placenta lambda sign at the site of insertion of membrane is indicator of $\mathrm{DC}$ and $\mathrm{T}$ sign is indicator of $\mathrm{MC}$.
Membrane thickness is important to differentiate at a later gestation when membrane is fused, generally second trimester and onwards when the insertion of intertwin membrane becomes less clear making difficult to identify lambda and $\mathrm{T}$ sign.

Due to unequal sharing of placenta monochorionic twin are having chances of complication like TTTs and SFGR. Various stages of TTTs are as follows; imbalance of amniotic fluid called oligo-poly sequence (stage 1), the bladder of donor twin is not visible and enlarged bladder in recipient twin (stage 2), abnormal colour doppler indices (stage 3), sign of heart failure in one of twin (stage 4) and there are demise of one or both twins (stage 5). Why there is SFGR in dichorionic pregnancy? The mechanism of IUGR is not very clearly understood. Various causes has been found like genetic factors and physical interaction at implantation resulting in a less favourable placental insertion in the uterus.

An excess of placental apoptosis and changes in synthesis of various trophoblastic proteins are found in discordant DC twins confirming the role of oxygenation, apoptosis, and oxidative stress in their growth disturbance. ${ }^{8}$ The etiology is unknown in the majority of DADC cases; however, twin-to-twin transfusion syndrome, in MAMC and $\mathrm{Rh}$ incompatibility, chromosomal and congenital abnormalities, preeclampsia, umbilical vein thrombosis, single umbilical artery, abnormalities arising from the location of placenta, and umbilical cord and uterine malformations are the main causes of fetal death in the rest of the cases. ${ }^{9,10}$

Generally demise of one twin in first trimester doesn't cause any problem for other growing twin but if fetal demise occurs after second trimester the problem of IUGR, PTL and chances of demise of other twin increases. The most dangerous maternal complication of after single fetal demise is coagulopathy but it's a rare complication which generally happens after three to four weeks after fetal demise. Therefore after single fetal demise coagulation profile should be considered every two weekly during conservative period of management. ${ }^{11}$

\section{METHODS}

This is a retrospective study done between Jul 2017-Jun 2020 at Command hospital, Panchkula, Haryana. Total 3249 deliveries has been conducted during above said period. Data analysis done by using WHO recommended computer software SPSS (statistical package for social sciences) version 17.0.1 December 2008. 47 deliveries were having twin pregnancy. Out of this 47 twin, 33 were DADC and 14 were DAMC twin pregnancy. Both monochorionic and dichorionic twin gestation has been included in study who did not have any comorbidity and who were willing to continue pregnancy with one fetus demise. Triplet pregnancy and fetal reduction cases has been excluded from study. We had six twin pregnancy who reported with one fetal demise and four of it were 
unbooked at this hospital and two were our follow-up patients. All six patients were followed till delivery with extensive monitoring and under supervision in maternity ward.

The difficult part was counseling of patients and relatives about complication because everyone had a layman opinion that poison spreads all over body if we continue pregnancy with one dead fetus. Patients and their relatives were counseled in detail. First of all when patient reported and diagnosed with one fetal demise patient has been admitted in maternity ward. Maternal and fetal monitoring started. Mother has been investigated for CBC, ABORh, TORCH IgG and IgM, Oral GTT with $75 \mathrm{gm}$ of glucose and viral markers.

Coagulation profile in form of PT, aPTT, INR, FDP and D-dimer and this coagulation profile has been repeated every week along with TLC till delivery. Clinical examination of patient continued everyday till delivery. For fetal monitoring baseline ultrasound for chorionicity and amnionicity (those who were unbooked at this hospital), fetal echo for monochrionic pregnancies, color Doppler, biophysical profile, amniotic fluid ,fetal growth parameters and any other sign of complication by monochorionic placenta. There was repeat ultrasound weekly to biweekly on case to case basis and fetal monitoring was done in form of DFMC, regular biophysical profile, daily NST and fetal growth parameter with doppler two weekly. These all six patients has been monitored and delivered as indoor patients till delivery injection dexamethasone four doses has been given at interval of $12 \mathrm{hrs}$ between 32 to 34 weeks anticipating preterm delivery. Either patient started labour pain or induced or taken directly for LSCS as per obstetric indication. All patients delivered beyond 36 weeks period of gestation and newborns were observed in NICU if required.

\section{RESULTS}

In our study all six mothers did not develop any antenatal or postpartum complication.During study period we delivered 3249 patients, out of which $47(1.44 \%)$ were twin pregnancies and out of this $14(29.69 \%)$ were DAMC and $33(70.31 \%$ ) were DADC. Six patients (four DADC and two DAMC) detected to have one fetal demise and they investigated for coagulation profile and infection regularly as per protocol. None of our patient developed any antenatal or postnatal complication. One pregnancy we carried out from 26 weeks to 36 weeks 02 days and delivered vaginally. All patients have been carried beyond 36 weeks. The longest duration we carried pregnancy from 26 weeks to 36 weeks 02 days. Out of these 06 patients 03 has been delivered vaginally and 02 underwent emergency LSCS and one elective LSCS for CDMR. Out of these 06 neonates 04 observed in NICU with no active intervention except only two, one who survived after TTTS required blood transfusion and other who had $\mathrm{Rh}$ isoimmunization and hydrops required phototherapy. In DADC twin pregnancies two had unexplained single fetal demise; one had single fetal demise due to complex cardiac disease and one because of Rh isoimmunization and fetal hydrops. In both DAMC twin pregnancies the cause of single fetal demise was TTTS. There was no structural deformity in any of twin who had demise in utero. The weight neonate varied from lowest $2.2 \mathrm{~kg}$ to highest $2.55 \mathrm{~kg}$.

Table 1: Age wise distribution of all patients.

\begin{tabular}{|l|l|}
\hline Age $($ years $)(\mathbf{n}=\mathbf{3 2 4 9})$ & $\mathbf{N}$ \\
\hline $\mathbf{2 0 - 2 5}$ & 495 \\
\hline $\mathbf{2 5 - 3 0}$ & 1520 \\
\hline $\mathbf{3 0 - 3 5}$ & 822 \\
\hline $\mathbf{3 5}-\mathbf{4 0}$ & 412 \\
\hline Mean age $\mathbf{S D}$ (years) & $29.49 \pm 4.41$ \\
\hline
\end{tabular}

First patient, 27 years old G2P1L1, unbooked at our hospital with previous full term normal vaginal delivery had DADC twin pregnancy and detected to have one fetal demise at 26 weeks. Mother and fetus had been monitored as per our protocol and pregnancy continued till 36 weeks 2 days. She developed spontaneous labour pain and delivered a female child of birth wt $2.3 \mathrm{~kg}$. New born observed for $24 \mathrm{hrs}$ in NICU and then handed over to mother in ward.

Table 2: Details of all patients.

\begin{tabular}{|c|c|c|c|}
\hline Nomenclature & $\mathbf{N}$ & Total & $\%$ \\
\hline Primigravida & 1865 & \multirow{2}{*}{3249} & 57.4 \\
\hline Multigravida & 1384 & & 42.6 \\
\hline Twin pregnancy & 47 & & 1.45 \\
\hline $\begin{array}{l}\text { Spontaneous } \\
\text { conceptions }\end{array}$ & 3173 & \multirow[t]{2}{*}{3249} & 97.6 \\
\hline ART conceptions & 76 & & 2.4 \\
\hline $\begin{array}{l}\text { Twin with SFD } \\
\text { (Single fetal demise) }\end{array}$ & 06 & & $\begin{array}{l}12.7 \text { of twin } \\
\text { gestation }\end{array}$ \\
\hline
\end{tabular}

Still born macerated with no external structural deformity. Cause of intrauterine death was unexplained. Second patient was 34 years old G3P2L2, with history of previous two full term normal vaginal delivery, unbooked at our hospital and reported first time at 33 weeks with mild discomfort of abdomen. Initial ultrasound was suggestive of monochorionic twin pregnancy with single fetal demise and ultrasound features were also suggestive of TTTS. Patient observed and monitored as per protocol in ward. She went in spontaneous labour at 36 weeks 5 days and underwent emergency LSCS because of secondary arrest of dialation of cervix and delivered a male baby of $2.2 \mathrm{~kg}$. Baby shifted to NICU and required blood transfusion twice and handed over to mother after two weeks of NICU management. Still born macerated with no structural external deformity. 
Table 3: Details of patients with single fetal demise.

\begin{tabular}{|lllllll|}
\hline $\begin{array}{l}\text { Age } \\
\text { (years) }\end{array}$ & Gravida & $\begin{array}{l}\text { Diagnosis of } \\
\text { IUD (weeks) }\end{array}$ & Cause of fetal demise & $\begin{array}{l}\text { Antepartum } \\
\text { Complication }\end{array}$ & $\begin{array}{l}\text { Delivery } \\
\text { (Weeks) }\end{array}$ & $\begin{array}{l}\text { Mode of } \\
\text { delivery }\end{array}$ \\
\hline $\mathbf{2 7}$ & G2P1L1 & 26 & Unexplained & Nil & $\begin{array}{l}36 \text { weeks } \\
\text { 02 days }\end{array}$ & $\begin{array}{l}\text { Vaginal } \\
\text { delivery }\end{array}$ \\
\hline $\mathbf{3 4}$ & G3P2L2 & 33 & TTTS & Nil & $\begin{array}{l}36 \text { weeks } \\
\text { 05 days }\end{array}$ & $\begin{array}{l}\text { Emergency } \\
\text { LSCS }\end{array}$ \\
\hline $\mathbf{2 5}$ & G3P1L1A1 & $\begin{array}{l}29 \text { weeks } \\
\text { 03 days }\end{array}$ & $\begin{array}{l}\text { Hydrops due to Rh } \\
\text { isoimmunization }\end{array}$ & Nil & 37 weeks & $\begin{array}{l}\text { Emergency } \\
\text { LSCS }\end{array}$ \\
\hline $\mathbf{2 6}$ & G2P1L1 & 30 & $\begin{array}{l}\text { Complex congenital heart } \\
\text { disease (Ebstien anamoly } \\
\text { in one fetus) }\end{array}$ & Nil & 37 weeks & $\begin{array}{l}\text { Elective } \\
\text { LSCS }\end{array}$ \\
\hline $\mathbf{2 9}$ & Primigravida & $\begin{array}{l}34 \text { weeks } \\
\text { 03 days }\end{array}$ & TTTS & Nil & $\begin{array}{l}36 \text { weeks } \\
\text { 04 days }\end{array}$ & $\begin{array}{l}\text { Vaginal } \\
\text { delivery }\end{array}$ \\
\hline $\mathbf{3 1}$ & Primigravida & 29 & Unexplained & Nil & $\begin{array}{l}36 \text { weeks } \\
\text { 05 days }\end{array}$ & $\begin{array}{l}\text { Vaginal } \\
\text { delivery }\end{array}$ \\
\hline
\end{tabular}

Table 4: Details of neonate and still born.

\begin{tabular}{|lllll|}
$\begin{array}{l}\text { Chorionicity and } \\
\text { amnionicity }\end{array}$ & $\begin{array}{l}\text { Any structural deformity in } \\
\text { dead fetus }\end{array}$ & $\begin{array}{l}\text { Birth weight } \\
\text { (neonate) (Kgs) }\end{array}$ & $\begin{array}{l}\text { Birth weight } \\
\text { (dead fetus) (Kgs) }\end{array}$ & $\begin{array}{l}\text { Postpartum } \\
\text { period }\end{array}$ \\
\hline DADC & Nil & 2.3 & 0.650 & Uneventful \\
\hline DAMC & Nil & 2.2 & 1.4 & Uneventful \\
\hline DADC & Nil & 2.7 & 1.2 & Uneventful \\
\hline DADC & Ebstien anamoly & 2.55 & 1.28 & Uneventful \\
\hline DADC & Nil & 2.2 & 1.76 & Uneventful \\
\hline DAMC & Nil & 2.45 & 1.29 & Uneventful \\
\hline
\end{tabular}

Third patient was 25 years old G3P1L1A1, unbookedat our hospital at 29 weeks 3 days period of gestation, reported from remote with an ultrasound report showing DADC twin pregnancy with one fetal demise and other was showing features of early hydrops.

On investigation detected to have $\mathrm{Rh}$ isoimmunization with ICT titer of 1:128 with MCA PSV more than 1.5 MoM. Patient planned for intrauterine transfusion. After cordocentesis one third volume of calculated doubly irradiated packed RBCs transfused in umbilical vein. Pretransfusion Hct was 15 and post transfusion Hct was 21. Two more transfusion given at weekly interval. After that patient given five more intrauterine transfusion on as and when required basis. Patient induced at 37 weeks but underwent emergency LSCS for fetal distress and delivered a male fetus of $2.7 \mathrm{~kg}$ and observed in NICU. No exchange transfusion or IVIg required and managed only with phototherapy. Still born macerated with no external structural deformity. Fourth patient was 26 years old G2P1L1, with previous history of LSCS, booked patient at our hospital, DADC twin pregnancy with known ebstien anamoly in one twin, detected to have intrauterine fetal demise of one twin who had ebstien anamoly at 30 weeks. Patient investigated as per our protocol and followed up. She underwent elective LSCS at 37 weeks and delivered a female child of $2.55 \mathrm{~kg}$. NICU management was not required for this newborn. Still born macerated with no external structural deformity. Fifth patient was 29 years old, unbookedat our hospital, primigravida with 34 weeks 03 days period of gestation, DADC twin pregnancy from reported in our OPD with history of leaking per vaginum for last 3 days. Ultrasound was suggestive of one fetal demise and

doppler and liquor for other twin were normal with normal growth parameters. Patient investigated as per protocol and managed with PPROM protocol. She underwent in to labour at 36 weeks 04 days and delivered a male child of $2.2 \mathrm{~kg}$. New born observed in NICU and then handed over to mother. Still born macerated with no external structural deformity. Sixth patient was 31 years old, primigravida, booked at our hospital, conceived after ovulation induction and timed intercourse, monochorionic twin pregnancy detected to have stage one TTTS at 29 weeks. She was admitted for observation and further management but after a week she went home against medical advice. She reported again in OPD at 33 weeks 04 days for checkup and detected to have fetal demise of one twin and other surviving twin with polyhydramnios. Patient counselled, investigated and followed up. Induced at 36 weeks 05 days and delivered a $2.45 \mathrm{~kg}$ male child. There was no requirement of NICU observation. Still born macerated with no external structural deformity.

\section{DISCUSSION}


The incidence of single fetal demise in our study was $12.76 \%$ which is much higher than study by Enbom in which the incidence reported from 3.5 to $7.8 \% .^{12}$ In our study the common cause of morbidity in monochorionic twin pregnancy was TTTS but this type of complication rarly happen with DADC twin pregnancy. In our study $33.3 \%$ had monochorionic placentation and all had one fetal demise because of TTTS.66.66\% had dichorionic placentation and out of which $50 \%$ had unexplained intrauterine fetal demise of one twin and one had complex cardiac disease and one had developed fetal hydrops due to $\mathrm{Rh}$ isoimmunization. However other studies like of Karl had monochorionic placentation in $83 \% .{ }^{13}$ In dichorionic twin the prognosis of surviving twin is good but in monochorionic twin there are chances of neurological damage because of severe hypotension in other twin when compromised twin is dying. ${ }^{14}$ Death of one fetus causes ischemic neurological damage of the other surviving twin by causing sudden hypotension which causes decreased blood supply to the twin. In DADC twin pregnancy demise of one fetus can cause sudden rupture of membrane between them and again causes hypotension and demise of other twin. Sometimes this type of complicated pregnancy with single fetal demise causes release of fibrin and tissue thromboplastin in circulation and leads to disseminated intravascular coagulation. If this happens chances of mortality is high for both mother and fetus. Another complication of this type of pregnancy are trans chorionic embolization and causes death of other fetus too. In our study we did not have any of these complications.

In current study we had a survival rate of $100 \%$ of mother and neonate as compare to the study of Landy and Fusi where mortality rate was $60 \% .{ }^{15}$ In most of the studies TTTS was detected to have most common cause of single fetal demise and in our study both monochorionic pregnancies had developed TTTS. ${ }^{16,17}$ In our study no patient developed DIC contrary to the study by Romero et al who find incidence of DIC to be $25 \% .{ }^{18}$ In other study by Aslan et al the reported median time interval between single fetal death and delivery was 11 days but we carried one pregnancy for 10 weeks two days after detection of one fetus demise. ${ }^{19}$ In our study the antenatal and post-natal period were absolutely uneventful and newborn were only observed in NICU except two.

\section{CONCLUSION}

Even with single fetal demise pregnancies can be continued till term with strict monitoring for maternal and fetal complications. Termination is not the only answer in twin pregnancies with single fetal demise. Twin pregnancy should be monitored very carefully from early to detect complications. Chorionicity and amnionicity should be established early and especially monochorionic pregnancy should be followed two weekly after second trimester to detect TTTS and other complications. If there is TTTS it should be treated with laser ablation of placental communication if available or patient has to referred in tertiary care centre where facilities are available. If we follow patient carefully with ultrasound and do fetal echo in all monochorionic pregnancy then we can diagnose and treat problems early and can prevent single fetal demise. Management plan should be individualized. Perinatal data suggest that the complications of twin pregnancy are due to pathophysiological changes in process of placentation. Perinatal mortality is high in monochorionic twin gestation as these pregnancies are at high risk for SFGR, TTTS than dichorionic twin pregnancies. These twin pregnancies especially monochorionic complications should be detected within time by ultrasound and treated accordingly. In dichorionic twin pregnancies the second and third trimester IUGR is generally due to either primary abnormal cord location or due to uteroplacental vascular abnormality. If abnormality such as placental abnormality, single umbilical artery or vasa previa detected by USG they can have a direct impact on outcome of pregnancy. Future research correlating antenatal findings and postnatal histopathological correlation from various studies in to a larger data will allow the further understanding of pathophysiology of this abnormality of cord and placenta. Good management and care can salvage more babies.

\section{Funding: No funding sources}

Conflict of interest: None declared

Ethical approval: The study was approved by the Institutional Ethics Committee

\section{REFERENCES}

1. Sunderam S, Kissin DM, Crawford SB, Folger SG, Jamieson DJ, Barfield WD, et al. Assisted reproductive technology surveillance-United States, 2011. MMWR Surveill Summ. 2014;63:1-28

2. ESHRE Capri Workshop Group. Multiple gestation pregnancy. Hum Reprod. 2000;15:1856-64

3. Steenhaut P, Hubinont C. Perinatal mortality in multiple pregnancy. Available at: www.intechopen. com. Accessed on 28 July 2015.

4. Jauniaux ERM. Multiple gestation pregnancy after assisted reproductive technology. London: Cambridge University Press; 2012:82-92.

5. Nejat EJ, Buyuk E. Reproductive technologies and the risk of birth defects. N Engl J Med. 2012;367(9):875.

6. McNamara HC, Kane SC, Craig JM, Short RV, Umstad MP. A review of the mechanisms and evidence for typical and atypical twinning. Am J Obstet Gynecol. 2013;45:52-9.

7. Bora SA, Papageorghiou AT, Bottomley C, Kirk E, Bourne T. Reliability of transvaginal ultrasonography at 7-9 weeks' gestation in the determination of chorionicity and amnionicity in twin pregnancies. Ultrasound Obstet Gynecol. 2008;32(5):618-21.

8. Krauss FT, Redline RW, Gersell DJ, Nelson DM, Dicke JM. Multiple pregnancy. In: Placental pathology. Washington: American Registry of Pathology; 2004:249-82. 
9. Peterson IR, Nyholm HCJ. Multiple pregnancies with single intrauterine demise: description of twenty-eight pregnancies. Acta Obstet Gynecol Scand. 1999;78: 202-6.

10. Baxi LV, Daftary A, Loucopoulos A. Single fetal demise in a twin gestation: Umbilical vein thrombosis. Gynecol Obstet Invest. 1998;46:266-67.

11. Axt R, Mink D, Hendrik J. Maternal and neonatal outcome of twin pregnancies complicated by single fetal death. J Perinat Med. 1999;27(3):221-7.

12. Enbom JA. Twin pregnancy with intrauterine death of one twin. Am J Obstet Gynecol. 1985;152:424-9.

13. Karl WM. Intrauterine death in a twin: implications for the survivor. In: Ward RH, Whittle M, editors. Multiple pregnancy. London: RCOG Press; 1995:218-30.

14. Fusi L, Gordon H. Twin pregnancy complicated by single intrauterine death. Problems and outcome with conservative management. $\mathrm{Br} \mathrm{J}$ Obstet Gynaecol. 1990;97:511-6.
15. Landy HJ, Weingord AB. Management of multiple gestation complicated by an antepartum fetal demise. Obstet Gynecol Surv. 1989;44:171-6.

16. Weiner AE, Ried DE, Roby CC. Coagulation defects with intrauterine death from $\mathrm{Rh}$ isosensitization. Am J Obstet Gynecol. 1950;60:1015.

17. Spellacy WN. Antepartum complications in twin pregnancies. Clin Perinatol. 1988;15:80-5.

18. Romero R, Duffy TP, Berkowitz RL. Prolongation of a preterm pregnancy complicated by death of a single twin in utero and disseminated intravascular coagulation: effects of treatment with heparin. N Engl J Med. 1984;310:772.

19. Aslan H, Gul A, Cebeci A. The outcome of twin pregnancies complicated by single fetal death after 20 weeks of gestation. Twin Res. 2004;7(1):1-4.

Cite this article as: Rai G, Mansingh S, Bhardwaj B. Maternal and neonatal outcome of twin pregnancies with single fetal demise. Int J Reprod Contracept Obstet Gynecol 2021;10:3095-100. 